\title{
Transformasi Wavelet dengan Teknik Clipping Filtering untuk Mereduksi PAPR pada OFDM
}

\author{
Ni Made Ary Esta Dewi Wirastuti ${ }^{1}$ dan Ida Bagus Dharma Dhyaksa ${ }^{2}$ \\ ${ }^{1}$ Program Studi Teknik Elektro, Fakultas Teknik, Universitas Udayana \\ Jl. Raya Kampus UNUD, Bukit Jimbaran, Badung, Bali, 80361, Indonesia \\ ${ }^{2}$ Garuda Maintenance Facility (GMF Aero Asia) \\ Bandara Soekarno - Hatta International Airport, Tangerang, Banten, 15126, Indonesia \\ dewi.wirastuti@unud.ac.id ${ }^{1}$,idabagusgdedharma@gmail.com ${ }^{2}$
}

\begin{abstract}
Orthogonal Frequency Division Multiplexing (OFDM) is chosen as multiplexing techniques and broadly used in today's radiocommunication environments to overcome spectrum insufficiency. With several superior advantages, however, OFDM is terribly affected by high peak to average power ratio (PAPR) due to offset frequency errors and local oscillator (LO) frequency synchronization errors. The high PAPR can cause nonl inear distortion, which outcomes in intermodulation and spectral leakage. This study aims to model the use of wavelet transform (discrete wavelet transform (DWT)) to replace Fourier transform (discrete Fourier transform (DFT)) that used in conventional OFDM, later in this paper is termed as DFTOFDM. Clipping fil tering techniques then applied to DWT-OFDM. The model was proposed to reduce PAPR in DFT-OFDM. The model was compared to DFT-OFDM using Matlab simulation method. The performance was eval uated using the Complementary Cumulative Distributive Function (CCDF) vs. PAPR. The results show that at PAPR $10^{-3}$ for DFT-OFDM, it was produced PAPR of $10.6 \mathrm{~dB}$ whereas in DWT-OFDM, using Daubechies orde 7 (Daubechies7), Symlet orde 7 (Symlet7), Coiflet orde 2 (Coiflet2), were reached PAPR 4.8 dB, PAPR 3.3 $\mathrm{dB}$, PAPR $3 \mathrm{~dB}$, respectively. It means Coiflet2 providing the best PAPR reduction among other orthogonal wavelets. By applied clipping fil tering to wavel et Coiflet2, it was produced PAPR of 2.9 dB for classical clipping and 2.8 dB for deep clipping. It show that wavelet Coiflet2 with deep clipping provided the best PAPR.
\end{abstract}

Keywords- OFDM, PAPR, discrete wavelet transform, discrete Fourier transform, clippingfiltering

\begin{abstract}
Abstrak- Orthogonal Frequency Division Multiplexing (OFDM) merupakan salah satu teknik multiplexing yang paling diunggulkan dan banyak digunakan dalam lingkungan sistem nirkabel untuk mengatasi kelangkaan spektrum. OFDM sangat dipengaruhi oleh efek yang tidak diinginkan dari kesalahan frekuensi offset dan frekuensi sinkronisasi pada osilator lokal sehingga menimbulkan tingginya Peak Average Power Ratio (PAPR). PAPR yang tinggi menyebabkan terjadinya distorsi nonlinier sehingga OFDM mengalami intermodulasi dan kebocoran spektral. Tujuan dari penelitian ini adalah memodelkan transformasi wavelet (discrete wavelet transform (DWT)) dengan menggantikan transformasi Fou rier (discrete Fourier transform (DFT)) yang biasa digunakan pada konvensional OFDM yang selanjutnya disebut dengan istilah DFT-OFDM. Teknik clipping filtering kemudian ditambahkan pada model DWT-OFDM. Sistem model yang diperkenalkan ini bertujuan untuk mereduksi PAPR pada DFT-OFDM. Tiga jenis orthogonal wavelet digunakan dalam penelitian ini, yaitu: Daubechies, Symlet, dan Coiflet, dengan pemilihan orde acak untuk masing-masing wavel et. Teknik clipping yang digunakan adalah classical dan deep clipping. Unjuk kerja sistem DWT-OFDM dan DFT-OFDM dibandingkan menggunakan metode simulasi dengan Matlab berdasarkan parameter Complementary Cumulative Distributive Function (CCDF) terhadap PAPR. Hasil penelitian menunjukkan bahwa pada saat CCDF 10-3, untuk DFT-OFDM menghasilkan PAPR 10,6 dB, sedangkan DWT-OFDM dengan wavel et Daubechies orde 7 (Daubechies7), Symlet orde 7 (Symlet7), Coiflet orde 2 (Coiflet2), menghasilkan PAPR 4,8 dB, 3,3 dB, dan $3 \mathrm{~dB}$, secara berurutan. Penggunaan DWT memberikan unjuk kerja yang lebih baik dibandingkan dengan menggunakan DFT. Wavelet Coiflet2 menghasilkan PAPR yang paling baik diantara ketiga jenis orthogonal wavelet. Dengan menambahkan clipping filtering pada wavelet Coiflet2 menghasilkan PAPR 2,9 dB saat classical clipping dan 2,8 dB saat deep clipping. Wavelet Coiflet2 dengan menambahkan deep clipping memberikan hasil reduksi PAPR yang paling baik.
\end{abstract}

Kata kunci-OFDM, PAPR, discrete wavelet transform, discrete Fourier transform, clippingfiltering

\section{PEndahuluan}

Teknologi sistem komunikasi terus berkembang untuk memenuhi kebutuhan akan kecepatan data yang tinggi.
Orthogonal Frequency Division Multiplexing (OFDM) yang berbasis discrete Fourier transform (DFT) menggunakan skema modulasi multicarrier (MCM) [1]. OFDM merupakan pesaing utama sistem komunikasi yang diperlukan untuk 
generasi berikutnya. Teknologi ini sangat menarik perhatian karena masih dapat mempertahankan performansinya dalam keadaan kanal yang buruk [2]. Sehingga OFDM telah banyak digunakan secara komersial dan masih tetap dalam pengembangan penelitian yaitu: Digital Video Broadcasting Terrestrial (DVB-T) [3], Wireless Local Area Network (WLAN) [4], Broadband Wireless Access (BWA) khususnya IEEE 802.16d WiMAX [5], [6], IEEE 802.20 mobile Broadband Wireless Access (BWA) dan Mobile Multimedia Access Communication (MMAC) [7] serta standar seluler $4^{\text {th }}$ Generation (4G) seperti Long Term Evolution (LTE) [8] [10].

OFDM sensitif terhadap frekuensi offset, phase noise, dan Peak-Average-Power Ratio (PAPR) yang tinggi [11], [12]. Dengan adanya PAPR yang tinggi diperlukan amplifier dengan rentang dinamis yang lebar sehingga dapat mencakup rentang nilai PAPR tersebut. Tetapi hal ini dapat menurunkan efisiensi amplifier. Penelitian untuk mereduksi nilai PAPR masih terus dilakukan, diantaranya melalui teknik clipping [13], clipping filtering [14], [15], selected mapping (SLM) [16] - [18], block coding [19], [20], partial transmit sequence (PTS) [21], dan tone reservation (TR) [22].

Diantara teknik-teknik yang digunakan mereduksi PAPR, teknik clipping filtering merupakan teknik yang paling sederhana dan paling banyak digunakan dengan memotong bagian-bagian dari sinyal yang berada di luar area yang diinginkan. Pemakaian metode clipping menghasilkan in band distortion dan out band radiation sinyal OFDM yang dapat menurunkan kinerja sistem. Dengan filtering dapat mengurangi out band radiation setelah clipping. Metode SLM melakukan beberapa rotasi vektor domain frekuensi asli dari sinyal OFDM, berdasarkan pada satu set vektor array yang telah ditetapkan. Untuk setiap varian sinyal yang diperoleh, PAPR yang sesuai dievaluasi, dengan PAPR terendah dipilih untuk transmisi. Metode PTS memiliki pendekatan yang sama dengan SLM dengan perbedaannya adalah sudut rotasi yang sama diterapkan ke lebih dari satu vektor. Setelah perhitungan PAPR dari masing-masing varian sinyal yang bersesuaian, PAPR minimal adalah dipilih untuk transmisi. Efisiensi metode SLM dan PTS meningkat dengan meningkatnya jumlah fase dari set yang dipertimbangkan. Kekurangannya adalah untuk mendapatkan efisiensi yang lebih baik membutuhkan peningkatan kompleksitas di sisi pemancar dan penerima. Teknik block coding tidak menimbulkan distorsi in band dan distorsi out band tetapi kerugiannya adalah meningkatnya kompleksitas jika subcarrier meningkat dan juga jika laju kode dikurangi, teknik ini mengalami efisiensi bandwidth. Penggunaan teknik TR tidak merusak ortogonalitas dari subcarrier tetapi meningkatkan kompleksitas pencarian sinyal pada domain waktu karena beberapa subcarrier yang tidak digunakan.

OFDM berbasis transformasi wavelet (discrete wavelet transform (DWT)) sedang diselidiki sebagai alternatif untuk menggantikan DFT yang digunakan dalam konvensional OFDM. Hal ini karena DWT pada OFDM dapat memberikan semua manfaat yang sama dengan DFT-OFDM yaitu diantaranya sama-sama dapat menghasilkan subcarrier dengan bandwidth dan panjang simbol yang berbeda serta kemampuannya dalam mengatasi intersymbol interference (ISI) dan intercarrier interference (ICI) dengan kelebihan tambahan dari DWT yaitu mengatasi PAPR yang tinggi dan frekuensi pembawa offset timing [23]. Berbeda dengan DFTOFDM, skema sistem wavelet memenuhi persyaratan untuk ortogonalitas dan mencapai rekonstruksi sempurna dengan menggunakan filter orthogonal dari bank quadrature mirror filter (QMF) [24]. Transformasi wavelet diskrit (discrete wavelet transform (DWT)) memiliki kepadatan spektral daya yang besar dibandingkan dengan DFT-OFDM karena DWT menghasilkan lobus samping (side lobe) yang padat dengan lobus samping yang lebih sempit terkandung energi dengan emisi out-of-band yang kecil.

Terdapat beberapa penelitian yang sudah membahas tentang DWT-OFDM [25] - [30]. Pada [25] membahas penggunaan adaptive DWT-OFDM pada pengolahan citra yang dibandingkan dengan adaptive DFT-OFDM, dimana adaptive DWT-OFDM memberikan unjuk kerja yang lebih bagus dari adaptive DFT-OFDM. Pada [26] menjelaskan penggunaan transformasi wavelet seperti discrete wavelet transform (DWT) dan double density discrete wavelet transforms (DDDWT) dapat meningkatkan unjuk kerja dari konvensional OFDM. Penurunan PAPR pada konvensional OFDM ditunjukkan pada hasil penelitian [27] dimana dengan memperkenalkan sistem OFDM menggunakan transformasi wavelet sebagai filter sinyal dan fungsi basis skala (scaling basis function). Pada [28], Bit Error Rate (BER) dari DWTOFDM dan FFT-OFDM dibandingkan dengan menggunakan variasi keluarga wavelet, yaitu: Haar, Daubechies, Biorthogonal, Reverse-Biorthogonal, dan Symlets. Hasil simulasi menunjukkan fungsi Haar memberikan BER yang paling baik dibandingkan dengan wavelet lainnya. Pemancar dan penerima DWT-OFDM untuk sistem komunikasi hybrid Powerline Communication (PLC) dan Visible Light Communication (VLC) diperkenalkan pada [29] yang menunjukkan unjuk kerja BER lebih baik dari sistem OFDM. Pada [30] membahas unjuk kerja DWT-OFDM dan FFTOFDM dalam menurunkan pengaruh ICI yang disebabkan oleh sampling frequency offset pada kanal Additive White Gaussian Noise (AWGN). Hasil simulasi menunjukkan dengan menggunakan DWT-OFDM berhasil menurunkan power dari ICI. Penelitian [13] tentang penggunaan teknik clipping untuk mereduksi PAPR pada OFDM. Penelitian lainnya tentang penggunaan teknik clipping filtering pada OFDM dilakukan pada [14], [15].

Kontribusi pada penelitian ini adalah pemodelan DWT yang menggantikan DFT pada konvensional OFDM dan menambahkan metode clipping filtering. Pemilihan clipping filtering berkaitan dengan implementasi yang sederhana dan komplesitas yang rendah. Pemodelan DWT dan clipping filtering dilakukan untuk mereduksi efek PAPR pada OFDM. Sedangkan pada penelitian-penelitian DWT-OFDM sebelumnya hanya menambahkan metode clipping saja tanpa filtering. Untuk menganalisa unjuk kerja sistem model, digunakan metode simulasi berdasarkan parameter Complementary Cumulative Distributive Function (CCDF) vs PAPR. Hasil penelitian dianalisa dengan membandingkan DFT-OFDM tanpa dan dengan menambahkan teknik clipping 
filtering dengan DWT-OFDM tanpa dan dengan menambahkan teknik clipping filtering.

Tulisan hasil penelitian ini disusun dalam empat bagian. Bagian I memperkenalkan tentang sistem OFDM serta penelitian-penelitian sebelumnya. Bagian II menguraikan model untuk mereduksi PAPR pada OFDM dengan menggunakan DWT-OFDM. Bagian III membahas tentang simulasi dan menganalisa hasil penelitian. Bagian IV menguraikan kesimpulan dari penelitian.

\section{METODE}

Penelitian ini memodelkan sistem OFDM berbasis transformasi Fourier (DFT-OFDM) dan transformasi wavelet (DWT-OFDM) dengan menggunakan teknik clipping filtering untuk mengurangi efek PAPR terhadap unjuk kerja sistem OFDM. Unjuk kerja kedua sistem dianalisa dengan menggunakan metode simulasi dengan melihat parameter CCDF terhadap PAPR.

Pertama, dilakukan simulasi PAPR pada sistem OFDM dengan transformasi Fourier (DFT-OFDM) untuk mengetahui PAPR, kemudian ditambahkan clipping filtering untuk mereduksi PAPR. Setelah itu dilakukan simulasi reduksi PAPR pada OFDM dengan transformasi wavelet (DWTOFDM), kemudian ditambahkan clipping filtering untuk melihat seberapa besar dapat mereduksi PAPR. Kemudian unjuk kerja DFT-OFDM dan DWT-OFDM dibandingkan.

\section{A. Pemodelan sistem}

Pemodelan DFT-OFDM, DFT-OFDM dengan clipping filtering, DWT-OFDM dan DWT dengan clipping filtering ditunjukkan pada Gambar 1, Gambar 2, Gambar 3, dan Gambar 4 secara berurutan.

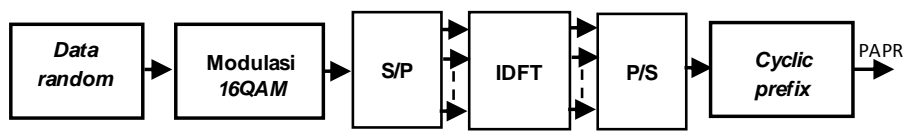

Gambar 1. Blok diagram DFT-OFDM

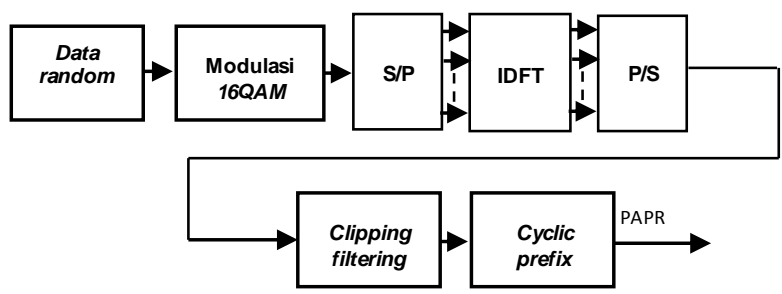

Gambar 2. Blok diagram DFT-OFDM dengan clipping filtering

Aliran data masukan dibangkitkan secara random atau acak kemudian dimodulasi oleh jenis modulasi (QPSK/QAM). Pada penelitian ini digunakan 16QAM. Sehingga menghasilkan aliran simbol 16-ary, di mana setiap simbol me miliki ko mponen dalam fase (I) dan kuadratur (Q), masingmasing mendefinisikan satu dari titik konstelasi yang mungkin. Aliran simbol ini dilewatkan melalui konverter serial-keparalel, yang menampilkan satu set simbol $N$-paralel $\mathrm{M}$-ary. Simbol-simbol luaran ini ditransmisikan melalui subchannel, $N$, dan sesuai dengan simbol yang ditransmisikan pada masing-masing sub-operator. Ju mlah bit informasi per-OFDM blok, tergantung pada jumlah subcarrier, $N$, dan jumlah bit per subcarrier, yang tergantung pada jenis modulasi yang digunakan. Selama setiap blok OFDM, setiap subcarrier mentransmisikan satu simbol.

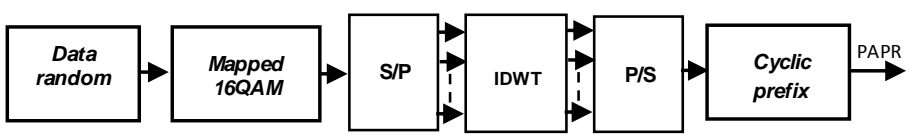

Gambar 3. Blok diagram DWT-OFDM

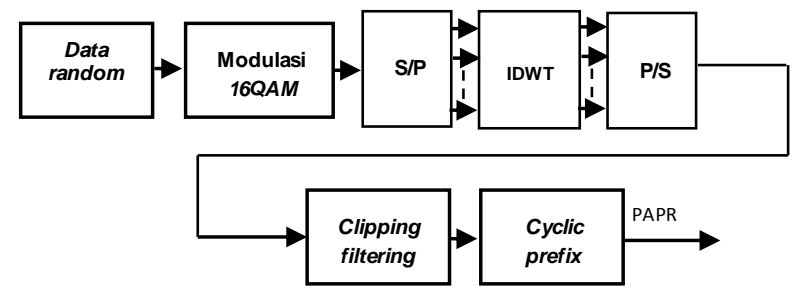

Gambar 4. Blok diagram DWT-OFDM dengan clipping filtering

Dengan demikian, simbol luaran dari konverter serial-keparalel adalah komponen frekuensi diskrit dari luaran OFDM modulator. Luaran OFDM modulator dihasilkan dengan mengubah komponen frekuensinya menjadi sampel waktu dengan melakukan inverse DFT (IDFT) pada subchannel. Setiap subchannel memodulasi pembawa terpisah melalui blok modulasi IDFT, yang menghasilkan blok OFDM. Sedangkan saat digunakan inverse DWT akan terjadi proses upsampling dan penyaringan menggunakan lowpass filter dan highpass filter untuk me misahkan ko mponen frekuensi rendah dan frekuensi tinggi. Proses ini disebut dengan dekomposisi. Pada penelitian ini digunakan deko mposisi tingkat 1 dan tidak menganalisa pengaruh perubahan tingkat dekomposisi pada DWT. Sesuai dengan tujuan dari penelitian ini adalah mereduksi PAPR sedangkan bila level dekomposisi wavelet ditingkatkan maka terjadi peningkatan PAPR.

Luaran dari IDFT mewakili sampel- $N$ dari blok OFDM dalam domain waktu. Urutan ini sesuai dengan sampel sinyal multicarrier, yang terdiri dari subchannel termodulasi linear. Urutan ini dikonversi paralel-ke-seri membentuk simbol OFDM dan kemudian awalan cyclic prefix dimasukkan untuk menghilangkan intersymbol interference (ISI). Sinyal masukan sebelum ke amplifier mengalami proses pemotongan (clipping). Teknik clipping ini sangat efektif digunakan untuk mereduksi nilai PAPR dimana hal ini disebabkan dengan teknik ini menyebabkan probabilitas terjadinya sinyal dengan peak yang tinggi menjadi sangat kecil. Akan tetapi terjadinya clipping yang nonlinear dapat mengakibatkan distorsi in-band yang mengakibatkan penurunan unjuk kerja sistem. Untuk mengatasi ini diakhir proses clipping dilakukan proses filtering untuk menurunkan out-of-band. Out-of-band yang tinggi dapat menyebabkan interferensi dengan kanal di sebelahnya.

\section{B. Teknik Clipping Filtering}

Prinsip dasar clipping adalah memotong sinyal yang mempunyai amplitudo lebih besar dari suatu nilai tertentu. Nilai tertentu tersebut disebut threshold atau nilai maksimum dengan [31]:

$$
\begin{gathered}
x(t)=s(t), \quad \text { untuk }|s(t)| \leq A \\
x(t)=A e^{j \varphi t} \text { untuk }|s(t)|>A ; \varphi t=\arg (s(t))
\end{gathered}
$$


dimana $x(t)$ adalah hasil clipping sinyal OFDM, $s(t)$ merupakan simbol OFDM dan A adalah nilai threshold clipping. Sinyal yang berada di bawah threshold akan dile watkan tanpa dipotong sehingga nilai input sama dengan nilai output. Clipping memotong amplitudo saja, sedangkan fasa dari sinyal tersebut tidak berubah. Nilai clipping maksimum ditentukan dengan mencari nilai clipping ratio (CR) menggunakan:

$$
C R=\frac{A_{\max }}{\sigma}
$$

dimana $\sigma$ adalah nilai root mean square (RMS) dari simbol OFDM. Kemudian dengan menggunakan (2) dapat ditentukan nilai maksimum dari threshold dengan $\sigma=\sqrt{N_{c}}$ :

$$
A_{\max }=C R \times \sqrt{N_{c}}
$$

dimana $N_{c}$ adalah jumlah subcarrier.

Metode clipping yang digunakan dalam penelitian ini adalah classical clipping dan deep clipping. Classical clipping telah diperkenalkan pada [32] adalah salah satu teknik clipping yang paling populer untuk mengurangi PAPR. Classical clipping ini memberikan efek pada kinerja OFDM, termasuk kepadatan spektral daya dan PAPR. Proses classical clipping menggunakan dua syarat, yaitu: amplitudo sinyal OFDM diloloskan langsung ketika amplitudo sinyal lebih kecil atau sama dengan nilai threshold, ketika sinyal $r$ pada kondisi lebih besar dari nilai ambang batas threshold maka sinyal akan mengalami proses clipping amplitudo sesuai dengan level CR. Sedangkan deep clipping telah diperkenalkan pada [32] untuk menyelesaikan masalah pertumbuhan kembali puncak amplitudo karena penyaringan out-of-band dari metode classical clipping. Jadi dalam teknik deep clipping, fungsi clipping dimodifikasi untuk memotong lebih mendalam puncak amplitudo yang tinggi. Proses deep clipping menggunakan tiga syarat, yaitu: amplitudo sinyal OFDM diloloskan langsung ketika amplitudo sinyal lebih kecil atau sama dengan nilai threshold. Ketika sinyal $r$ pada kondisi $A_{\max }<r \leq \frac{1+p}{p} A_{\max }$, maka sinyal mengalami proses clipping dengan persamaan $A-p *(r-A)$. Ketika $r>\frac{1+p}{p} A_{\max }$, maka amplitudo sinyal akan mengalami proses clipping dengan nilai amplitudo " 0 ". Dimana $p$ adalah tingkat kedalaman clipping (deep factor) yang telah ditentukan sebelumnya.

Gambar 5 dan Gambar 6 menunjukkan karakteristik classical dan deep clipping. Pada Gambar 5 dan Gambar 6, "without clipping" artinya pada saat amplitudo tanpa proses clipping namun melebihi nilai dari threshold sehingga posisinya berada di atas threshold. Untuk classical clipping pada Gambar 5 menunjukkan amplitudo sinyal yang melebihi threshold mengalami proses pemotongan yang sesuai dengan level CR. Sedangkan proses deep clipping pada Gambar 6 menunjukkan amplitudo yang melebihi threshold mengalami proses clipping sesuai level CR lalu proses tersebut akan memotong lebih dalam lagi pada puncak amplitudo sesuai dengan tingkat kedalaman (deep factor) yang telah ditentukan sebelumnya.

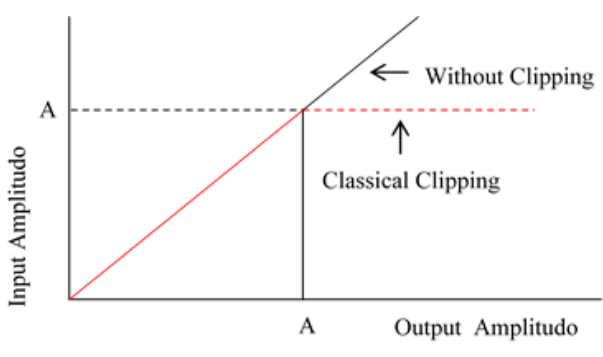

Gambar 5. Karakteristik classical clipping

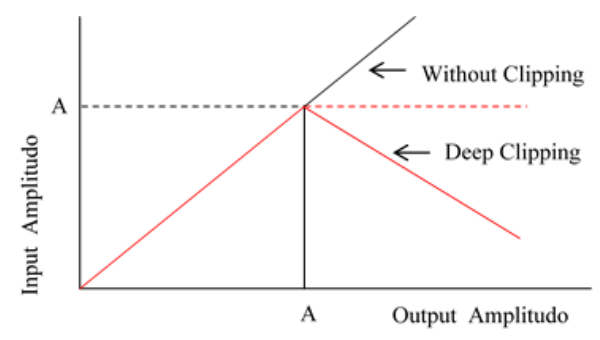

Gambar 6. Karakteristik deep clipping

\section{Parameter Simulasi}

Untuk mengetahui unjuk kerja dari pe modelan sistem yang disebutkan pada Gambar 1 hingga Gambar 4 digunakan metode simulasi dengan menggunakan perangkat lunak Matlab. Pada simulasi ini mempergunakan tiga jenis wavelet orthogonal yang fungsi-fungsinya telah didukung oleh Matlab. Parameter yang digunakan pada simulasi dapat dilihat pada Tabel I.

TABEL I. PARAMETER SIMULASI

\begin{tabular}{|l|l|}
\hline \multicolumn{1}{|c|}{ Parameter } & \multicolumn{1}{c|}{ Nilai } \\
\hline Jumlah frame & 5000 \\
\hline Clipping ratio (CR) & $\begin{array}{l}\text { Classical clipping }=1,4 \\
\text { Deep clipping }=0,6\end{array}$ \\
\hline Ukuran FFT & 64 \\
\hline Jumlah subcarriers & 64 \\
\hline $\begin{array}{l}\text { Jumlah bit dalam 1 simbol } \\
\text { OFDM }\end{array}$ & 64 \\
\hline Jumlah simbol & 1 \\
\hline Jumlah cyclic prefix & $1 / 4$ dari jumlah subcarriers \\
\hline Total simbol & $\begin{array}{l}\text { Jumlah subcarriers }+ \text { jumlah } \\
\text { cyclic prefix }\end{array}$ \\
\hline
\end{tabular}

\section{HASIL DAN PEMBAHASAN}

Dengan menggunakan model DFT-OFDM pada Gambar 1 dan Gambar 2 diperoleh hasil simulasi CCDF vs. PAPR seperti pada Gambar 7. Pada grafik, DFT-OFDM tanpa clipping filtering ditulis dengan istilah OFDM konvensional (pemodelan pada Gambar 1). Fungsi statistik CCDF digunakan untuk menganalisis dan membandingkan nilai PAPR, baik tanpa menambahkan teknik clipping filtering dan dengan menggunakan teknik clipping dan filtering. Parameter simulasi menggunakan nilai pada Tabel I.

Gambar 7 menunjukkan bahwa pada DFT-OFDM saat CCDF $10^{-3}$ menghasilkan PAPR 11,2 dB. Dengan menambahkan teknik classical clipping menghasilkan PAPR 4,1 dB. Ini berarti classical clipping mampu mereduksi PAPR sebesar 7,1 dB. Untuk deep clipping menghasilkan PAPR 4,6 
$\mathrm{dB}$, artinya mampu mereduksi PAPR sebesar 6,6 dB. Jadi pada saat teknik clipping filtering diaplikasikan pada DFTOFDM, sistem mengalami nilai PAPR yang lebih baik daripada OFDM tanpa aplikasi clipping filtering dengan deep clipping menghasilkan nilai reduksi yang paling baik. Nilai threshold pada amplitudo yang dibatasi pada perlakuan teknik clipping ini mampu menciptakan nilai puncak amplitudo lebih kecil dari nilai rata-rata amplitudo. Sehingga penambahan teknik clipping bis a mereduksi nilai PAPR.

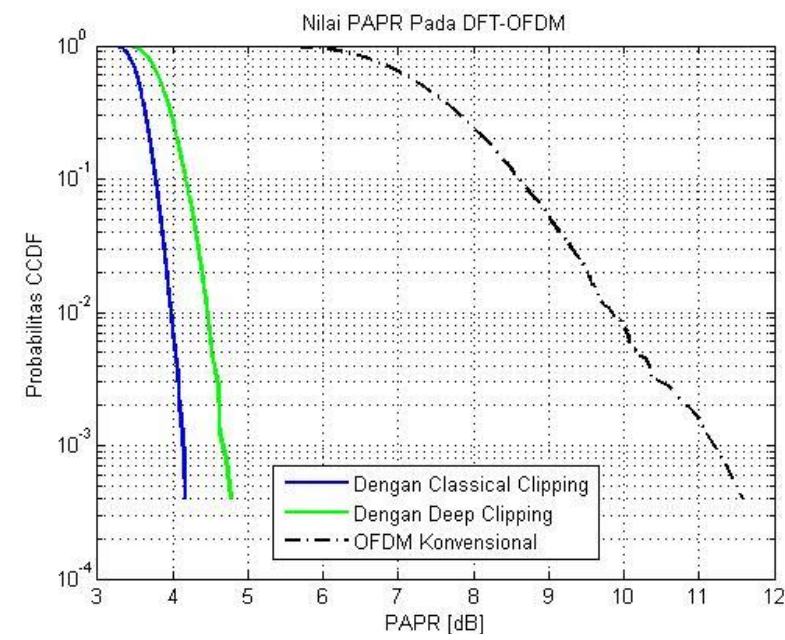

Gambar 7. Nilai PAPR DFT-OFDM dengan dan tanpa clipping filtering

Gambar 8 hingga Gambar 10 menunjukkan hasil simulasi DWT-OFDM dengan menggunakan pemodelan DWT-OFDM pada Gambar 3. Terdapat tiga jen is wavelet orthogonal yang dipergunakan dalam simulasi, yaitu: wavelet Daubechies, wavelet Symlet, dan wavelet Coiflet serta menggunakan parameter simulasi seperti pada Tabel I. Kemudian hasil simulasi masing-masing wavelet dibandingkan dengan DFTOFDM. Pada grafik, DFT-OFDM tanpa clipping filtering ditulis dengan istilah OFDM konvensional (pemodelan pada Gambar 1). Tujuan simulasi ini adalah untuk menentukan jenis wavelet yang paling baik dalam mereduksi PAPR. Setelah diperoleh jenis wavelet yang paling baik dalam mereduksi PAPR selanjutnya ditambahkan teknik clipping filtering hanya pada jenis wavelet yang memberikan unjuk kerja sistem yang paling baik tersebut.

Gambar 8 menunjukkan hasil simulasi DWT-OFDM dengan menggunakan wavelet Daubechies. Simulasi dilakukan dengan mengambil sample dari beberapa orde (n) wavelet Daubechies secara acak, yaitu: orde 6-20. Dari Gambar 8 dapat dilihat bahwa saat CCDF $10^{-3}$ pada DFTOFDM dihasilkan PAPR sebesar 10,6 dB. Wavelet Daubechies mampu mereduksi PAPR paling besar adalah Daubechies7 (db7) menghasilkan PAPR 4,6 dB, artinya mampu mereduksi PAPR sebesar $6 \mathrm{~dB}$. Sedangkan wavelet Daubechies mampu mereduksi PAPR paling kecil adalah Daubechies20 (db20) menghasilkan PAPR $8 \mathrm{~dB}$, artinya mampu mereduksi PAPR sebesar 2,6 dB. Hasil simulasi menunjukkan bahwa ada kecenderungan apabila semakin tinggi nilai orde pada Daubechies (Daubechies n) maka nilai PAPR yang dapat direduksi semakin kecil, begitu juga sebaliknya apabila semakin kecil nilai orde pada Daubechies
(Daubechies n) maka nilai PAPR yang dapat direduksi semakin besar.

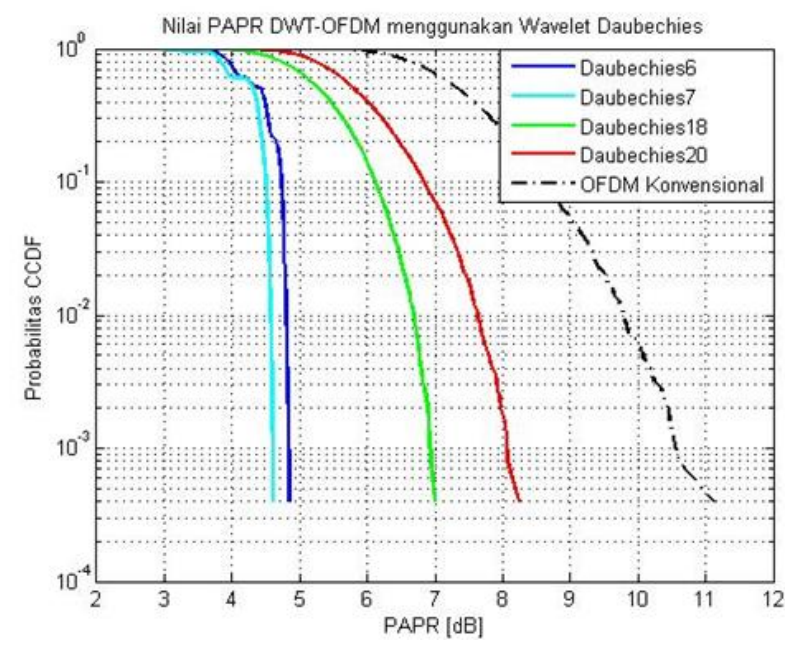

Gambar 8. Nilai PAPR DWT-OFDM menggunakan wavelet Daubechies

Wavelet Symlet merupakan modifikasi dari wavelet Daubechies dalam hal peningkatan kesimetrian pada saat mempertahankan bentuk yang paling sederhana, maka dari itu properti dari wavelet Daubechies dan wavelet Symlet hampir sama. Simulasi dilakukan menggunakan wavelet Symlet dengan orde acak dari orde 7 sampai 11. Dari Gambar 9, saat CCDF $10^{-3}$ pada DFT-OFDM menghasilkan PAPR sebesar 10,6 dB. Symlet7 (Sy m7) mampu mereduksi PAPR paling besar yaitu menghasilkan PAPR 3,3 dB, artinya mampu mereduksi PAPR sebesar 7,3 dB. Sedangkan Symlet11 (Sym11) mampu mereduksi PAPR paling kecil yaitu menghasilkan PAPR 4,5 dB, artinya mampu mereduksi PAPR sebesar 6,1 dB. Jadi hasil simulasi menunjukkan bahwa semakin tinggi nilai orde pada Symlet (Sy mlet $n$ ) maka nilai PAPR yang dapat direduksi semakin kecil, begitu juga sebaliknya semakin kecil nilai orde pada Symlet (Symlet $n$ ) maka nilai PAPR yang dapat direduksi semakin besar [30]. Hal ini sama dengan yang terjadi pada Daubechies, dimana sebelumnya telah dijelaskan apabila diantara kedua keluarga wavelet ini memiliki karakteristik yang hampir sama [33].

Pada penelitian DWT-OFDM menggunakan wavelet Coiflet digunakan orde 2 sampai 5. Dari Gambar 10 pada saat CCDF $10^{-3}$ untuk DFT-OFDM menghasilkan PAPR 10,6 dB. Coiflet (Coif2) mereduksi PAPR paling besar dengan menghasilkan PAPR $3 \mathrm{~dB}$, artinya mampu mereduksi PAPR sebesar 7,6 dB dari PAPR DFT-OFDM. Sedangkan Coiflet5 (Coif5) mereduksi PAPR paling kecil dengan menghasilkan PAPR sebesar 4,1 dB yang artinya mampu mereduksi PAPR sebesar 6,5 dB dari PAPR DFT-OFDM. Jadi unjuk kerja wavelet Coiflet tidak jauh beda dengan keluarga wavelet orthogonal lainnya yaitu jika semakin tinggi nilai orde pada Coiflet (Coiflet $\mathrm{n}$ ) maka nilai PAPR yang dapat direduksi semakin kecil, begitu juga sebaliknya semakin kecil nilai orde pada Coiflet (Coiflet $n$ ) maka nilai PAPR yang dapat direduksi semakin besar. Dari hasil simulasi, jenis wavelet yang mampu mereduksi PAPR paling baik adalah wavelet Coiflet2 (Coif2). 
Jumlah vanishing moment merupakan properti penting dari fungsi wavelet yang merupakan parameter untuk menyatakan kemampuan wavelet dalam merepresentasikan sifat polinomial yang menentukan koefisien filter wavelet. Semakin baik filter dalam me lakukan pemilihan frekuensi hal in i berarti semakin banyak filter yang dimiliki oleh wavelet. Wavelet Coiflet mampu mereduksi PAPR dengan nilai lebih besar dikarenakan memiliki jumlah vanishing moment $2 \mathrm{n}$ lebih panjang dibandingkan fungsi wavelet Daubechies dan Symlet [33]. Hal ini juga menyebabkan Coiflet memiliki nilai reduksi yang lebih rapi dibandingkan dengan Daubechies dan Symlet karena dengan jumlah vanishing moments yang lebih panjang menyebabkan nilai koefisien filter yang lebih banyak artinya filter bekerja lebih baik.

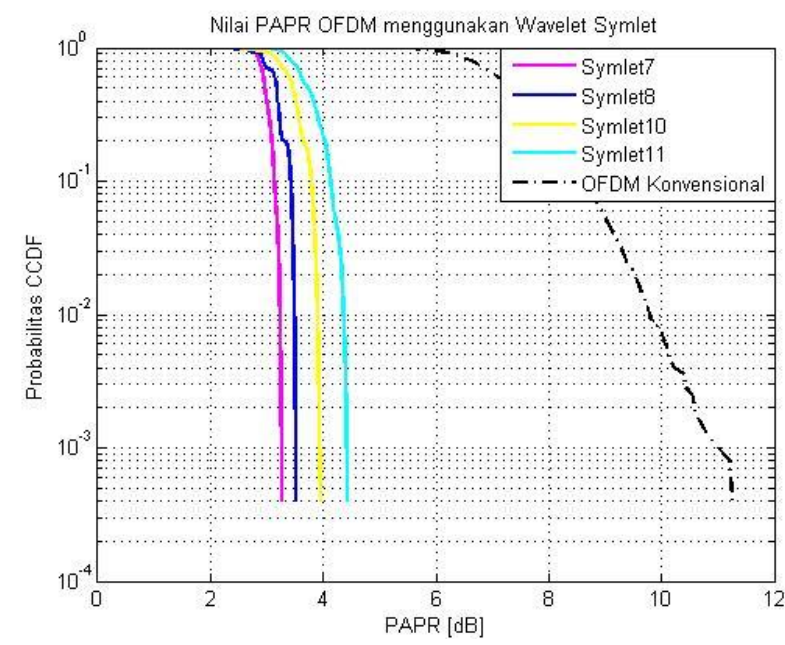

Gambar 9. Nilai PAPR DWT-OFDM menggunakan wavelet Symlet

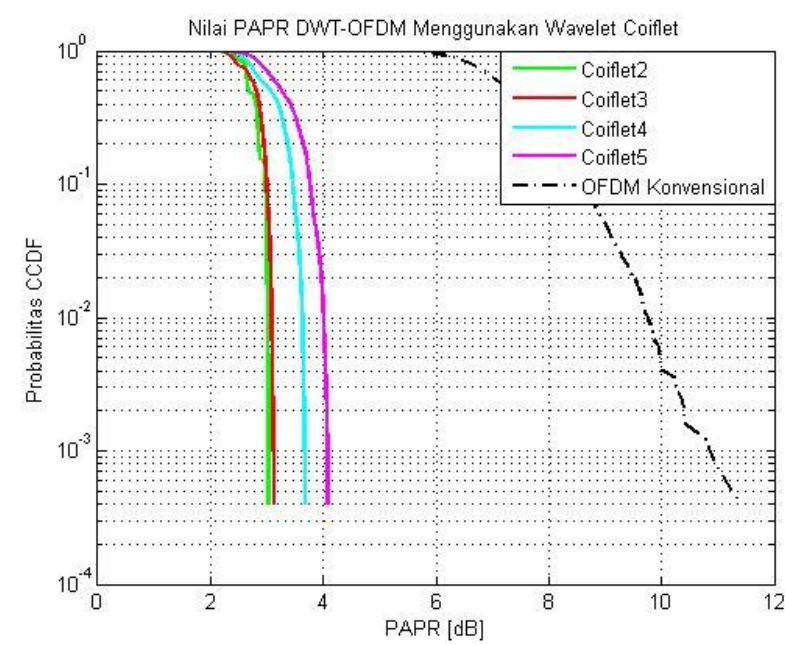

Gambar 10. Nilai PAPR DWT-OFDM menggunakan wavelet Coiflet

Kemudian untuk mengetahui unjuk kerja keluarga wavelet yang mampu mereduksi PAPR paling baik pada OFDM yaitu wavelet Coif2, dilakukan simulasi baik tanpa proses clipping dan filtering, dengan classical clipping dan filtering serta deep clipping dan filtering, dibandingkan dengan unjuk kerja DFTOFDM. Gambar 11 menunjukkan pada saat $\mathrm{CCDF}=10^{-3}$, nilai PAPR pada DFT-OFDM adalah $10,8 \mathrm{~dB}$. Saat menggunakan wavelet Coif2 tanpa penambahkan clipping filtering menghasilkan PAPR 3,4 dB, art inya mampu mereduksi PAPR dari DFT-OFDM sebesar 7,4 dB. Sementara itu, wavelet Coif2 dengan menggunakan classical clipping memiliki nilai PAPR sebesar 2,9 dB, artinya mampu mereduksi PAPR dari DFT-OFDM sebesar 7,9 dB. Jen is wavelet Coif2 dengan deep clipping menghasilkan PAPR sebesar $2,8 \mathrm{~dB}$, artinya wavelet Coif2 mampu mereduksi PAPR sebesar $8 \mathrm{~dB}$ dari DFTOFDM. Hasil simulasi menunjukkan bahwa wavelet Coif2 dengan deep clipping dan filtering mempunyai unjuk kerja yang lebih baik dalam mereduksi PAPR pada OFDM dibandingkan wavelet Coif2 dengan classical clipping dan filtering.

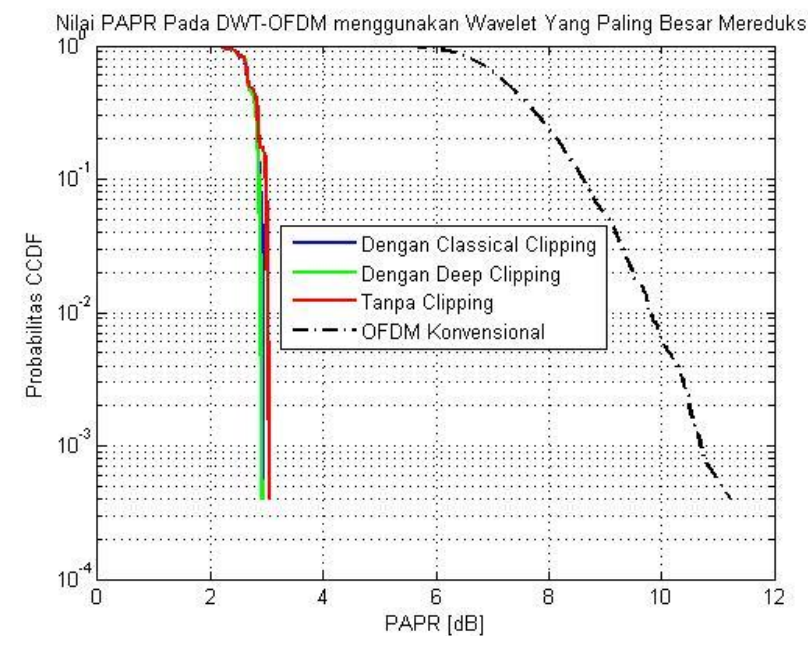

Gambar 11. Perbandingan CCDF vs. PAPR menggunakan wavelet Coiflet2, dengan classical dan deep clipping

Tabel II merupakan rangkuman hasil simulasi dari empat pemodelan sistem DFT-OFDM dan DWT-OFDM dengan dan tanpa penambahan teknik clipping filtering seperti pada Gambar 1 hingga Gambar 4 menggunakan parameter pada Tabel I.

TABEL II. RANGKUMAN HASIL SIMULASI

\begin{tabular}{|l|c|c|}
\hline \multicolumn{1}{|c|}{ Sistem Model } & Nilai PAPR & Nilai Reduksi \\
\hline DFT-OFDM & $11,2 \mathrm{~dB}$ & 0 \\
\hline DFT-OFDM dengan clipping filtering \\
\hline - Classical clipping & $4,1 \mathrm{~dB}$ & $7,1 \mathrm{~dB}$ \\
\hline - Deep clipping & $4,6 \mathrm{~dB}$ & $6,6 \mathrm{~dB}$ \\
\hline DWT-OFDM \\
\hline - Wavelet Daubechies (db7) & $4,6 \mathrm{~dB}$ & $6,0 \mathrm{~dB}$ \\
\hline - Wavelet Symlet (Sym7) & $3,3 \mathrm{~dB}$ & $7,3 \mathrm{~dB}$ \\
\hline - Wavelet Coiflet (Coif2) & $3,0 \mathrm{~dB}$ & $7,6 \mathrm{~dB}$ \\
\hline DWT-OFDM dengan clipping filtering (Coif2) \\
\hline - Classical clipping & $2,9 \mathrm{~dB}$ & $7,9 \mathrm{~dB}$ \\
\hline - Deep clipping & $2,8 \mathrm{~dB}$ & $8,0 \mathrm{~dB}$ \\
\hline
\end{tabular}

\section{PENUTUP}

Dengan menggunakan transformasi wavelet dan teknik clipping filtering, nilai PAPR pada DFT-OFDM dapat direduksi lebih baik dibandingkan dengan menggunakan teknik clipping filtering tapi tanpa tranformasi wavelet. Jenis wavelet yang mampu mereduksi PAPR paling baik adalah wavelet Coif 2 yaitu sebesar 7,6 dB sedangkan $\mathrm{db} 76 \mathrm{~dB}$ dan Sym7 7,3 dB. Wavelet Coif 2 mampu mereduksi PAPR dengan 
nilai lebih besar diantara keluarga wavelet orthogonal lainnya. wavelet Coif2 dengan menambahkan deep clipping dan filtering memberikan hasil reduksi PAPR yang paling baik yaitu $8 \mathrm{~dB}$.

\section{REFERENSI}

[1] R. Nissel, S. Schwarz, and M. Rupp, "Filter Bank Multicarrier Modulation Schemes for Future Mobile Communications," IEEE Journal on Selected Areas in Communications, vol. 35, no. 8, pp. 1768-1782, Aug. 2017, doi: 10.1109/JSAC.2017.2710022.

[2] J. Choi, "On the Error Rate Analysis of Coded OFDM Over Multipath Fading Channels," IEEE Wireless Communications Letters, vol. 8, no. 2, pp. 536-539, April 2019, doi: 10.1109/LWC.2018.2878820.

[3] G. Bournaka, M. Ummenhofer, D. Cristallini, J. Palmer, and A. Summers, "Experimental Study for Transmitter Imperfections in DVB$\mathrm{T}$ Based Passive Radar," IEEE Transactions on Aerospace and Electronic Systems, vol. 54, no. 3, pp. 1341-1354, June 2018, doi: 10.1109/TAES.2017.2785518

[4] A. Makki, A. Siddig, M. M. Saad, C. J. Bleakley, and J. R. Cavallaro, "High-resolution time of arrival estimation for OFDM-based transceivers," in Electronics Letters, vol. 51, no. 3, pp. 294-296, 52 2015, doi: 10.1049/el.2014.3677.

[5] S. R. Band, M. S. Dorle, and S. S. Dorle, "BER performance of WIMAX system using wavelet packet modulation technique," in 2016 World Conference on Futuristic Trends in Research and Innovation for Social Welfare (Startup Conclave), Coimbatore, 2016, pp. 1-5, doi: 10.1109/STARTUP.2016.7583917.

[6] N. Sharma, I. Deb, A. Jain, and B. Bhattacharyya, "Physical Layer Performance Analysis of MIMO-WiMAX on Simulink," in 2018 Intemational Conference on Communication and Signal Processing (ICCSP), Chennai, 2018, pp. 979-983, doi: 10.1109/ICCSP.2018.8524293.

[7] I. Lazov, "Entropy Analysis of Broadband Wireless Access Systems," IEEE Systems Journal, vol. 11, no. 4, pp. 2366-2373, Dec. 2017, doi: 10.1109/JSYST.2015.2456941.

[8] Y. A. Al-Jawhar, K. N. Ramli, A. Mustapha, S. A. Mostafa, N. S. Mohd Shah, and M. A. Taher, "Reducing PAPRW ith Low Complexity for 4G and 5G Waveform Designs," IEEE Access, vol. 7, pp. 9767397688,2019, doi: 10.1 109/ACCESS.2019.2930121.

[9] I. Selinis, K. Katsaros, M. Allayioti, S. Vahid, and R. Tafazolli, "The Race to 5G Era; LTE and Wi-Fi," IEEE Access, vol. 6, pp. 5659856636,2018, doi: 10.1109/ACCESS.2018.2867729.

[10] K. Jallouli, M. Mazouzi, A. B. Ahmed, A. Monemi, and S. Hasnaoui, "Multicore MIMO-OFDM LTE Optimizing," in 2018 International Conference on Internet of Things, Embedded Systems and Communications (IINTEC), Hamammet, Tunisia, 2018, pp. 166-170, doi: 10.1109/IINTEC.2018.8695290.

[11] P. Mathecken, T. Riihonen, S. Werner, and R. Wichman, "Phase Noise Estimation in OFDM: Utilizing Its Associated Spectral Geometry," IEEE Transactions on Signal Processing, vol. 64, no. 8, pp. 1999-2012, April15, 2016, doi: 10.1109/TSP.2015.2512532.

[12] T. H. Pham, S. A. Fahmy, and I. V. McLoughlin, "Efficient Integer Frequency Offset Estimation Architecture for Enhanced OFDM Synchronization," IEEE Transactions on Very Large-Scale Integration (VLSI) Systems, vol. 24, no. 4, pp. 1412-1420, April 2016, doi: 10.1109/TVLSI.2015.2453207.

[13] S. K. Vangala and S. Anuradha, "Analysis and comparison of clipping techniques for OFDM/OQAM peak-to-average power ratio reduction," 2015 International Conference on Applied and Theoretical Computing and Communication Technology (iCATccT), Davangere, 2015, pp. 791-795, doi: 10.1109/ICATCCT.2015.7456990.

[14] I. Sohn and S. C. Kim, "Neural Network Based Simplified Clipping and Filtering Technique for PAPR Reduction of OFDM Signals," IEEE Communications Letters, vol. 19, no. 8, pp. 1438-1441, Aug. 2015, doi: 10.1 109/LCOMM.2015.2441065.

[15] K. Anoh, C. Tanriover, B. Adebisi, and M. Hammoudeh, "A New Approach to Iterative Clipping and Filtering PAPR Reduction Scheme for OFDM Systems," IEEE Access, vol. 6, pp. 17533-17544, 2018, doi: 10.1109/ACCESS.2017.2751620.
[16] D. J. G. Mestdagh, J. L. Gulfo Monsalve, and J. -. Brossier, "GreenOFDM: a new selected mapping method for OFDM PAPR reduction," Electronics Letters, vol. 54, no. 7, pp. 449-450, 2018, doi: 10.1049/el.2017.4743.

[17] D. J. G. Mestdagh, J. L. Gulfo Monsalve, and J. -. Brossier, "GreenOFDM: a new selected mapping method for OFDM PAPR reduction," in Electronics Letters, vol. 54, no. 7, pp. 449-450, 54 2018, doi: 10.1049/el.2017.4743

[18] T. Kageyama and O. Muta, "A Partial Scrambling Overlapped Selected Mapping PAPR Reduction Scheme for OFDM/OQAM Systems," in 2019 7th Intemational Japan-Africa Conference on Electronics, Communications, and Computations, (JAC-ECC), Alexandria, Egypt, 2019, pp. 37-40, doi: 10.1109/JAC-ECC48896.2019.9051096.

[19] A. Idris, N. L. Mohd Sapari, M. Syarhan Idris, S. S. Sarnin, W. Norsyafizan Wan Mohamad, and N. F. Naim, "Reduction of PAPR Using Block Coding Method and APSK Modulation Techniques for FOFDM in 5G System," in TENCON 2018 - 2018 IEEE Region 10 Conference, Jeju, Korea (South), 2018, pp. 2456-2460, doi: 10.1109/TENCON.2018.8650304.

[20] A. Idris, N. L. Mohd Sapari, M. Syarhan Idris, S. S. Sarnin, W. Norsyafizan Wan Mohamad, and N. F. Naim, "Reduction of PAPR Using Block Coding Method and APSK Modulation Techniques for FOFDM in 5G System," TENCON 2018 - 2018 IEEE Region 10 Conference, Jeju, Korea (South), 2018, pp. 2456-2460, doi: 10.1109/TENCON.2018.8650304.

[21] B. Cai, A. Liu, X. Liang, and F. Cheng, "A Class of PAPR Reduction Methods for OFDM Signals Using Partial Transmit Sequence," in 2019 IEEE 8th Joint Intemational Information Technology and Artificial Intelligence Conference (ITAIC), Chongqing, China, 2019, pp. 861-865, doi: 10.1109/ITAIC.2019.8785763.

[22] V. Tran and N. Ha, "Improving Peak-to-Average Power Ratio Reduction for OFDM Signals Using Modified Tone Reservation and Clipping-and-Filtering Hybrid Scheme," 2018 Engineering and Telecommunication (EnT-MIPT), Moscow, Russia, 2018, pp. 61-65, doi: 10.1109/EnT-MIPT.2018.00020.

[23] J. Pang, S. Ni, F. Wang, S. Han, S. You, X. Li, M. Luo, and Z. Liu, "Performance Analysis of FSO System Using FFT-OFDM and DWTOFDM," in 2019 24th OptoElectronics and Communications Conference (OECC) and 2019 International Conference on Photonics in Switching and Computing (PSC), Fukuoka, Japan, 2019, pp. 1-3, doi: 10.23919/PS.2019.8817782.

[24] F. A. Pinto-Benel, M. Blanco-Velasco, and F. Cruz-Roldán, "Throughput Analysis of Wavelet OFDM in Broadband Power Line Communications," IEEE Access, vol. 6, pp. 16727-16736, 2018, doi: 10.1109/ACCESS.2018.2796618.

[25] A. Mannan and A. Habib, "Adaptive processing of image using DWT and FFT OFDM in AWGN and Rayleigh channel," in 2017 Intemational Conference on Communication, Computing and Digital Systems (C-CODE), Islamabad, 2017, pp. 346-350, doi: 10.1109/CCODE.2017.7918955.

[26] D. L. Rani, M. Bharathi, and N. Padmaja, "Performance Comparison of FFT, DCT, DWT and DDDWT-OFDM in Rayleigh Channel," in 2019 Intemational Conference on Smart Systems and Inventive Technology (ICSSIT), Tirunelveli, India, 2019, pp. 392-394, doi: 10.1109/ICSSIT 46314.2019.8987953.

[27] J. Lee and H. Ryu, "Design and Comparison of Discrete Wavelet Transform Based OFDM (DWT-OFDM) System," in 2018 Tenth Intemational Conference on Ubiquitous and Future Networks (ICUFN), Prague, 2018, pp. 881-885, doi: 10.1109/ICUFN.2018.8437028.

[28] M. S. Sheela, T. P. Surekha, and K. R. Arjun, "Analysis of BER in OFDM using Wavelet and FFT based Method," in 2017 International Conference on Current Trends in Computer, Electrical, Electronics and Communication (CTCEEC), Mysore, 2017, pp. 473-476, doi: 10.1109/CTCEEC.2017.8455191.

[29] S. Baig, H. Muhammad Asif, T. Umer, S. Mumtaz, M. Shafiq, and J. Choi, "High Data Rate Discrete Wavelet Transform-Based PLC-VLC Design for 5G Communication Systems," IEEE Access, vol. 6, pp. 52490-52499, 2018, doi: 10.1109/ACCESS.2018.2870138. 
Jurnal Teknik Elektro Vol. 12 No. 1

Januari - Juni 2020

[30] G. Waichal and A. Khedkar, "Performance Analysis of FFT Based OFDM System and DWT Based OFDM System to Reduce Intercarrier Interference," in 2015 International Conference on Computing Communication Control and Automation, Pune, 2015, pp. 338-342, doi: 10.1109/ICCUBEA.2015.71.

[31] Hanna Bogucka, Adrian Kliks, Pawel Kryszkiewicz, "Advanced Multicarrier Technologies for Future Radio Communication: $5 G$ and Beyond", John Wiley \& Sons, 2017.

[32] Brahim Bakkas, Reda Benkhouya, Idriss Chana and Hussain Ben-Azza, "Palm Date Leaf Clipping: A New Method to Reduce PAPR in OFDM Systems", Information 2020, 11, 190; doi:10.3390/info11040190

[33] L. Yu and L. B. White, "Complex rational orthogonal wavelet and its application in communications," in IEEE Signal Processing Letters, vol. 13, no. 8, pp. 477-480, Aug. 2006, doi: 10.1109/LSP.2006.874393. 